\title{
Development of portable traditional triple mouth chula
}

\author{
M. N. Hoque, M. S. Rahman and N. Nahar \\ Department of Farm Structure, Bangladesh Agricultural University, Mymensingh-2202, Bangladesh
}

\begin{abstract}
In rural areas of Bangladesh almost in every house earthen Chula is used for cooking purpose. Mostly single mouth Chula is used in this purpose. The Heat Use Efficiency (HUE) of this Chula is needed to be increased by proper design for better utilization of fire wood to reduce the cost of cooking especially in the rural areas of Bangladesh. In this regard the effect of dimensions such as hearth height and diameter of the traditional single-mouth Chula on HUE were tested. The effects of dimensions of triple mouth Chula on HUE were also tested. Thus varieties of single mouth and triple mouth Chula both series and triangular were constructed. The variations of triple mouth Chula were made on size and shape, fuel inlet and exit, providing stone and without stone, providing lid and without lid etc. The HUE of single mouth Chula was found varied from $17.02 \%$ to $22.3 \%$.The maximum HUE of triple mouth Chula was found varied from $31.52 \%$ to $39.74 \%$. The highest HUE of this Chula was found to be $39.74 \%$ in earthen Chula encased with iron drum. This most efficient Chula has identity of separate air entry with stone, fuel inlet and smoke and ash exit at bottom. It is portable and its cost is with in the afford of rural people. It can be made even cheaper by making with only soil. Thus it can be produced commercially which can save fire wood, money as well as time of the user.
\end{abstract}

Keywords: Heat use efficiency, Portable, Triple mouth Chula

\section{Introduction}

Biomass is the most important primary source of energy in many countries of the world. It is the oldest type of fuel which people used for centuries after discovery of fire itself. About $50 \%$ of the world population depends principally on the biomass for their primary source of energy and approximately two billion people in the third world use fuel wood as a primary source of energy because of its availability, ease in collection, simplicity of uses and possibility of storing over seasons.

Mainly the traditional wood burning Chula are used for cooking and processing of food materials in the rural people of Bangladesh. The Chula is dug underground and the pots are remaining at ground level. There are some disadvantages of using these Chula such as non-portable, require more fire wood, low heat use efficiency and time consuming. Several investigators reported that the efficiency of traditional Chula is 5-11\% (Islam, 1980; Khan and Hasan, 1989; Hossain and Alam, 1994). Also day by day the amount of biomass is reduced for increase of population and deforestation. So technology should be improved for efficient use of biomass.

Many researchers worked on traditional stove to improve its performance such as smoke free, personal comfort, time saving, fuel saving etc but that require damper, air inlet, combustion chamber, grate, chimney, ash pit and cowl which are not only easily available but also costly. Their efficiency was estimated at 20-40\% (Islam, 1980; Prashad, 1987). Though the traditional stoves work with very low efficiency, almost all the rural people use the traditional wood stoves. As they are continuing to use the traditional wood stoves, it is necessary to change its design feature and find the optimum dimensions of the stoves with a view to improve its performance as well as maximize HUE.

In this connection Islam (2007) developed a triple mouth Chula with best dimension combination and maximum heat use efficiency was found to be $37.71 \%$. Hossain (2008) constructed Chula above ground and modified with lids instead of providing stone. He found maximum heat use efficiency $37.27 \%$ for series type and $43.31 \%$ for triangular type Chula. Thus it was observed that modification, dimension combination and proper design resulted in increase heat use efficiency. Hence the aim of this project is to construct varieties of portable Chula and to study the performance of single mouth and triple mouth portable Chula. 


\section{Materials and Methods}

The experiment was conducted at the Concrete and Materials Testing Laboratory of the Department of Farm Structure, Bangladesh Agricultural University. The traditional Chula is made underground providing earthen stone fixed to support the pots and giving facility of fuel and air inlet. The hearth height and diameter depend on the size of the pot mainly. A portable Chula is characterized to be moved when necessary. So it is to be constructed above ground detaching earth surface. Thus different types of Chula were constructed as portable Chula. Mostly two types Chula were made, single mouth and triple mouth. Both of these have two types: i) Earthen body ii) Iron drum encased body. Again earthen body Chula was used with lid and without lid. The body was made of only clay soil and lid was made with concrete mortar (cement, sand and surki at 1:2:3 proportions), lime mortar (lime and surki were mixed at 1:2 proportion) and only with clay soil. Wire net was provided with the concrete mortar to prevent crack in the lid. The lid for the single mouth Chula was round shape having opening in the middle and for series type triple mouth Chula was rectangular having three circular opening and for triangular Chula having three opening placed at $60^{\circ}$ angle. The body and the lids all were portable and replaceable. The fuel inlet and smoke exit system were changed differently to study the HUE.

\section{Size and shape of the Chula}

While making Chula shape, size was maintained properly. The selection of size (diameter) was done on the basis of pot size so that they can be set on the Chula easily. The single mouth Chula was round shape keeping hearth diameter $15 \mathrm{~cm}$ and $18 \mathrm{~cm}$ and hearth height $20 \mathrm{~cm}, 23 \mathrm{~cm}, 26 \mathrm{~cm}$ and $29 \mathrm{~cm}$ respectively. Fire wood inlet diameter was $11 \mathrm{~cm}$. One to three holes were provided for aeration and exit gases. The triple mouth series type Chula was rectangular shape and triangular triple mouth Chula was triangular or almost round shape. Hearth diameters were16 cm, $18 \mathrm{~cm}, 20 \mathrm{~cm}$ and $22 \mathrm{~cm}$ and corresponding hearth heights were $20 \mathrm{~cm}, 23 \mathrm{~cm}, 26 \mathrm{~cm}$ and $29 \mathrm{~cm}$ respectively. Fuel inlet for every Chula was $11 \mathrm{~cm}$. Three holes were provided sideways for aeration and exit of gases.
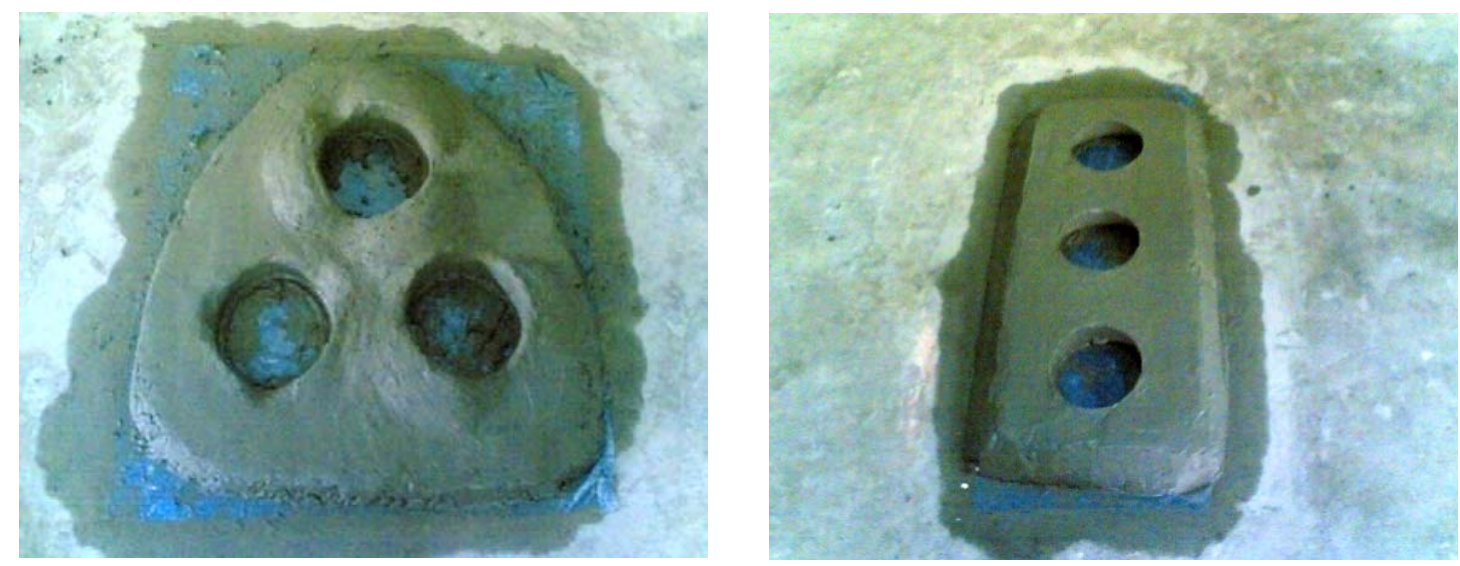

Fig.1 The photographic view of triple mouth ( Triangular and Series) Chula with concrete lids

\section{Heat use efficiency}

Heat use efficiency (HUE) of the Chula was determined by the following equation:

$$
\begin{aligned}
& \text { HUE }=\frac{\text { Heat output }}{\text { Heat input }} \times 100 \\
& =\frac{(\mathrm{MwCpw}+\mathrm{MuCpu})\left(T_{2}-\mathrm{T}_{1}\right)+\mathrm{MeL}}{\mathrm{M}_{\mathrm{j}} \mathrm{B}_{\mathrm{j}}}
\end{aligned}
$$


Where,

HUE= Overall heat use efficiency of Chula (\%), $M_{u}=$ Mass of utensil $\left({ }^{\circ} \mathrm{C}\right), M_{W}=$ Amount of water taken $(\mathrm{Kg}), \mathrm{M}_{\mathrm{e}}=$ Amount of water evaporated $(\mathrm{kg})$,

$\mathrm{T}_{1}=$ Initial temperature of water and utensil $\left({ }^{\circ} \mathrm{C}\right), \mathrm{T}_{2}=$ Final Temperature of water and utensil $\left({ }^{\circ} \mathrm{C}\right)$,

$\mathrm{C}_{\mathrm{pw}}=$ Mean specific heat of water $\left(\mathrm{kJ} / \mathrm{kg}^{\circ} \mathrm{C}\right), \quad \mathrm{C}_{\mathrm{pu}}=$ Mean specific heat of utensil $\left(\mathrm{kJ} / \mathrm{kg}{ }^{\circ} \mathrm{C}\right)$,

$\mathrm{L}=$ Latent heat of evaporation $(\mathrm{kJ} / \mathrm{kg})$,

$\mathrm{B}_{\mathrm{J}}=$ Calorific value of jute stick $(\mathrm{kJ} / \mathrm{kg})$ $\mathrm{M}_{\mathrm{j}}=$ Amount of Jute stick burned $(\mathrm{kg})$,

\section{Determination of Heat use efficiency}

In this experiment Water boiling method was used for determination of HUE. Dry jute stick was used as fuel, the calorific value of it was $12765.5 \mathrm{~kJ} / \mathrm{kg}$. Initially the weight of utensil, water, and jute sticks were measured by a balance. The initial temperature of water was recorded by the help of a thermometer. The temperature of utensil was assumed to be the same as the temperature of water. Jute sticks were burned and burning continued until the water becomes boiled. Final temperature of water was recorded. The unused jute stick was weighed.

\section{Construction of model Chula}

Considering the results obtained from a series of trial Chula, a model Chula was constructed as shown in Figure 3. Iron drum of $38 \mathrm{~cm}$ diameter was used as enclosure of the earthen Chula having handle to move it easily. The upper part was enlarged sufficiently to hold 3 pots easily. It was provided with fuel inlet hole. The air entry facility was maintained by using stone making shape like traditional rural Chula. Exit opening hole was provided at the bottom. Steel bar baffle was provided at middle supports fuel wood at middle and ash deposited at bottom. However this model Chula can be modified for different types of pots, fire wood, volume of cooking etc.

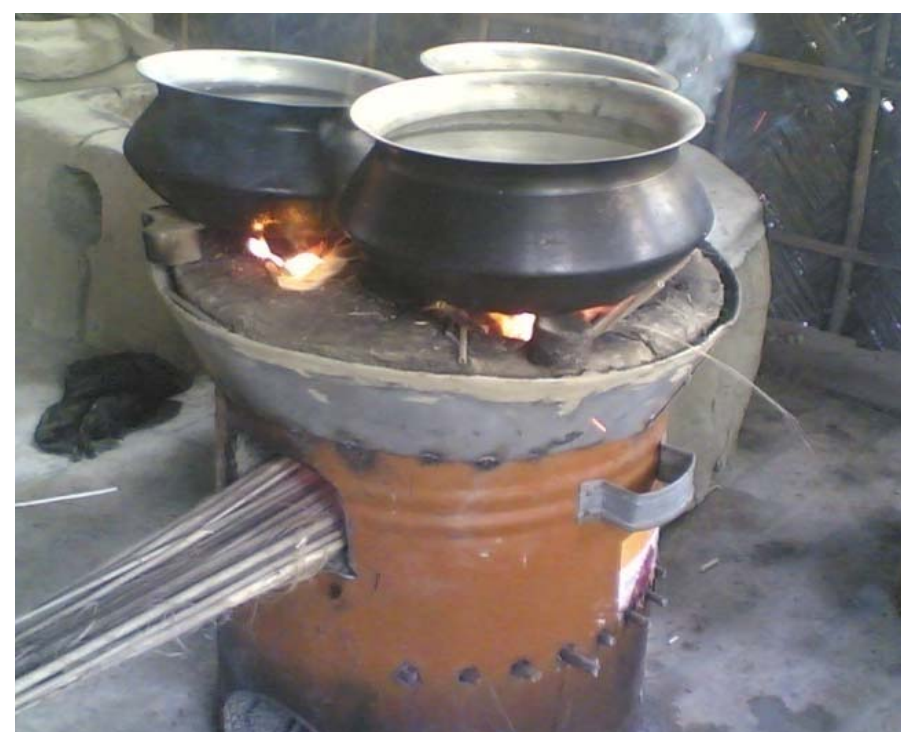

Figure.3 Photographic view of triangular triple mouth model Chula

\section{Study on model Chula}

A study was done on model Chula to compare the fire wood consumption for same type of cooking dish. Rice, chicken curry and pulse of similar amount were cooked at the same time in three different single mouth Chula, series Chula, triangular Chula and triangular type model Chula. The amount of fire wood used in each type of Chula was recorded 


\section{Results and Discussion}

Heat use efficiency (HUE) of single mouth Chula was found different varying hearth height and hearth diameter. The HUE of single mouth Chula for different dimensions is given in Table 1. It was found that the heat use efficiency was maximum for hearth height $23 \mathrm{~cm}$ and hearth diameter of $18 \mathrm{~cm}$. Similar results were obtained by Hossain (2008) in this type Chula.

Table 1. Heat use efficiency of single mouth Chula without lid

\begin{tabular}{|c|c|c|c|}
\hline Hearth height $(\mathrm{cm})$ & Hearth diameter $(\mathrm{cm})$ & Ratio of hearth height and dia. & Efficiency (\%) \\
\hline 20 & 18 & 1.111 & 17.02 \\
\hline 23 & 18 & 1.278 & 22.3 \\
\hline 26 & 18 & 1.444 & 19.81 \\
\hline 29 & 18 & 1.611 & 15.22 \\
\hline
\end{tabular}

The heat use efficiency of series and triangular type triple mouth Chula for different dimensions is given in Table 2. For series type triple mouth Chula the HUE of different size of Chula was found to vary from $24.32 \%$ to $31.19 \%$. The maximum efficiency was found for hearth height $26 \mathrm{~cm}$ and hearth diameter of 20 $\mathrm{cm}$. For triangular type triple mouth Chula the HUE varied from $31.52 \%$ to $39.74 \%$ and the maximum heat use efficiency was found for hearth height $26 \mathrm{~cm}$ and hearth diameter $20 \mathrm{~cm}$. It was also found that triangular triple mouth Chula gave maximum HUE.

Table 2. Heat use efficiency of triple mouth Chula without lid

\begin{tabular}{|c|c|c|c|c|}
\hline \multirow{2}{*}{ Hearth height $(\mathrm{cm})$} & \multirow{2}{*}{$\begin{array}{c}\text { Hearth diameter } \\
(\mathrm{cm})\end{array}$} & $\begin{array}{c}\text { Ratio of hearth height } \\
\text { and dia. }\end{array}$ & \multicolumn{2}{|c|}{ Efficiency (\%) } \\
\cline { 4 - 5 } & 16 & 1.25 & 27.45 & 32.21 \\
\hline 20 & 18 & 1.27 & 24.32 & 35.65 \\
\hline 23 & 20 & 1.3 & 31.19 & 39.74 \\
\hline 26 & 22 & 1.31 & 29.15 & 31.52 \\
\hline 29 & & &
\end{tabular}

Heat use efficiency of triple mouth Chula with lid are given in Table 3 and it was found that HUE was low compare with triple mouth Chula without lid. The reason may be the concrete lid absorbed enough heat.

Table 3. Heat use efficiency of triple mouth Chula with lid

\begin{tabular}{|c|c|c|c|c|}
\hline \multirow{2}{*}{ Type of Chula } & $\begin{array}{c}\text { Hearth } \\
\text { height }(\mathrm{cm})\end{array}$ & Hearth diameter $(\mathrm{cm})$ & $\begin{array}{c}\text { Ratio of hearth } \\
\text { height and dia. }\end{array}$ & Efficiency (\%) \\
\hline \multirow{2}{*}{ Series } & 20 & 16 & 1.25 & 24.45 \\
\cline { 2 - 5 } & 23 & 18 & 1.27 & 22.12 \\
\hline \multirow{2}{*}{ Triangular } & 20 & 16 & 1.25 & 27.22 \\
\cline { 2 - 5 } & 23 & 18 & 1.27 & 23.15 \\
\hline
\end{tabular}

A comparison of maximum heat use efficiency of different types Chula is given in Table 4. It was observed that highest HUE was found from triangular triple mouth at hearth height $26 \mathrm{~cm}$ and hearth diameter 20 $\mathrm{cm}$. The reason for the higher HUE of triple mouth type Chula than the single type is due to more use of heat by the three pans rather than single and complete burning of fuel by proper aeration.

Table 4. Comparison of heat use efficiency for different types of Chula

\begin{tabular}{|c|c|c|c|c|}
\hline Type of Chula & $\begin{array}{c}\text { Hearth height } \\
(\mathrm{cm})\end{array}$ & $\begin{array}{c}\text { Hearth diameter } \\
(\mathrm{cm})\end{array}$ & $\begin{array}{c}\text { Ratio of hearth } \\
\text { height and dia. }\end{array}$ & $\begin{array}{c}\text { Efficiency } \\
(\%)\end{array}$ \\
\hline Single mouth & 23 & 18 & 1.28 & 22.3 \\
\hline Series type triple mouth & 26 & 20 & 1.3 & 31.19 \\
\hline Triangular triple mouth & 26 & 20 & 1.3 & 39.74 \\
\hline
\end{tabular}


Table 5 shows the variation of fuel used in different Chula for similar dishes. In comparison to single mouth Chula series type Chula saved $22.03 \%$, triangular type Chula saved $38.90 \%$ and newly developed model Chula saved $42.37 \%$ fuel. The model Chula can be constructed commercially and its cost would be less than Tk.500/- encased in iron drum and Tk.100/- if it is made with only soil. Rural interested person can be trained-up to make it.

Table 5. Comparison of fuel used for similar dishes

\begin{tabular}{|l|c|c|c|}
\hline \multicolumn{1}{|c|}{ Type of Chula } & $\begin{array}{c}\text { Amount of fuel wood } \\
\text { used gm }\end{array}$ & $\begin{array}{c}\text { Save with respect to } \\
\text { single mouth }\end{array}$ & $\%$ of fuel saving \\
\hline 3 single mouth Chula & 2950 & - & - \\
\hline Series Chula & 2300 & 650 & 22.03 \\
\hline Triangular Chula & 1800 & 1150 & 38.90 \\
\hline Model Chula & 1700 & 1250 & 42.37 \\
\hline
\end{tabular}

\section{Conclusions}

On the basis of the results of the study it can be concluded that the triple mouth Chula was found to be least fuel consumable. The heat use efficiency of single mouth, series triple mouth and triangular triple mouth Chula were found to be $22.3 \%, 31.19 \%$ and $39.74 \%$ respectively The Chula both single mouth and triple mouth having lid was found not efficient. The triangular type Chula performed best which should be popularized. Iron drum encased triangular Chula as made model Chula was found most efficient Chula which will save time of cooking also and this can be produced commercially. The country will be benefited if it is widely used all over the country.

\section{References}

Hossain, M.M. and Alam, M.M. 1994. Improvement of the efficiency of traditional Chula. J. Agril. Mach. \& Mcsch., 1(1): 73-78.

Hossain, M.S. 2008. A study on modified Chula. Project Work and Report, Department of Farm Structure, Bangladesh Agricultural University, Mymensingh.

Islam, N. 1980. Study of problems and prospects of biogas technology as a mechanism for rural development. Study in a pilot area of Bangladesh, Department of Chemical Engg. BUET, Dhaka, p.97.

Islam, M.S. 2007. Development and performance evaluation of triple mouth Chula. M.S. Thesis, Department of Farm Structure, Bangladesh Agricultural University, Mymensingh.

Khan, R. and Hasan, R. 1989. Cook stove in Bangladesh- A case study. A Publication from the wood burning stove group. Eindhoven University of Technology, Netherlands, May 1989, p.5.

Prashad, K. 1987. Wood fired heaters- "Biomass" renewable energy. Edited by Hall and Overend, John Wiley and Sons Publication London, No.20, p.413. 